\title{
Full-endoscopic Trans-Kambin's Triangle Lumbar Interbody Fusion: Technique and Review of Literature
}

\author{
Koichi Sairyo ${ }^{1}$, Masatoshi Morimoto ${ }^{1}$, Kazuta Yamashita ${ }^{1}$, Fumitake Tezuka ${ }^{1}$, Kosuke Sugiura ${ }^{1}$, Makoto Takeuchi ${ }^{1}$, \\ Kiyoshi Yagi, Kazuya Kishima, Junzo Fujitani ${ }^{1}$, Yoichiro Takata ${ }^{1}$, Toshinori Sakai ${ }^{1}$, Toru Maeda ${ }^{1}$ \\ ${ }^{1}$ Department of Orthopedics, Tokushima University, Tokushima, Japan \\ ${ }^{2}$ Sports and Nutrition Clinic, Fukuoka, Japan
}

Corresponding Author:

Koichi Sairyo, MD, PhD

Department of Orthopedics, Tokushima

University Graduate School, 3-18-15

Kuramoto, Tokushima 770-8503, Japan

TEL: +81-88-633-7240

FAX: +81-88-633-0178

Email: sairyokun@hotmail.com

Received: February 25, 2021

Revised: March 21, 2021

Accepted: March 21, 2021
Transforaminal full-endoscopic (fullendo) lumbar surgery was first introduced as a method for performing discectomy. More recently, it has been used for decompression of lumbar spinal canal stenosis. The fullendo technique can also be performed for lumbar interbody fusion (LIF) through Kambin's triangle. Similar techniques have been used to insert a cage using fullendo surgery and are described variously in the literature as percutaneous endoscopic LIF, percutaneous endoscopic transforaminal LIF, full-endoscopic LIF, and full-endoscopic transforaminal LIF. Given that a cage is inserted through Kambin's triangle, we have proposed that this method be known as fullendo trans-Kambin's triangle lumbar interbody fusion (fullendoKLIF). We have recently created a fullendo-KLIF surgical system. In this paper, we describe our surgical procedure, report the initial clinical results, and review similar fullendo LIF techniques reported in the literature.

Key Words: Fullendo-KLIF, Kambin's triangle, Interbody fusion, Full-endoscopic surgery

\section{INTRODUCTION}

In the 1980s, Kambin identified the anatomic corridor now known as Kambin's triangle ${ }^{1,2)}$ as a minimally invasive method for accessing the intradiscal space (Figure 1). This route is different from the traditional interlaminar approach and was introduced after percutaneous discectomy ${ }^{3)}$, which was first described by Hijikata, ${ }^{1,2}$. After several trials that used an endoscopic approach to negotiate Kambin's triangle, the currently used single-portal full-endoscopic surgical system was developed by Yeung ${ }^{4,5}$.

Transforaminal (TF) full-endoscopic (fullendo) surgery was initially used for discectomy ${ }^{4-6)}$. The indication for TF-fullendo was then expanded to include decompression of spinal canal steno$\mathrm{sis}^{7}$. Foraminal stenosis was the initial target for decompression using TF-fullendo surgery because the intervertebral foramen is anatomically close to the entry point for the TF approach ${ }^{8,9)}$. The next indication was lateral recess stenosis ${ }^{7)}$. To decompress the lateral recess using the TF approach, the ventral side of the facet joint needs to be removed ${ }^{10,11)}$. Therefore, Sairyo et al. coined the term "ventral facetectomy" to describe TF-fullendo surger ${ }^{10)}$. The final step was decompression of central canal stenosis. The method developed by Sairyo et al. ${ }^{12)}$ included removal of all of the superior articular process and partial removal of the inferior articular process using a TF approach, allowing wide exposure of the thickened ligamentum flavum compressing the cauda equina. The thickened ligamentum flavum can be removed using a specially designed Kerrison rongeur. This surgical techni-

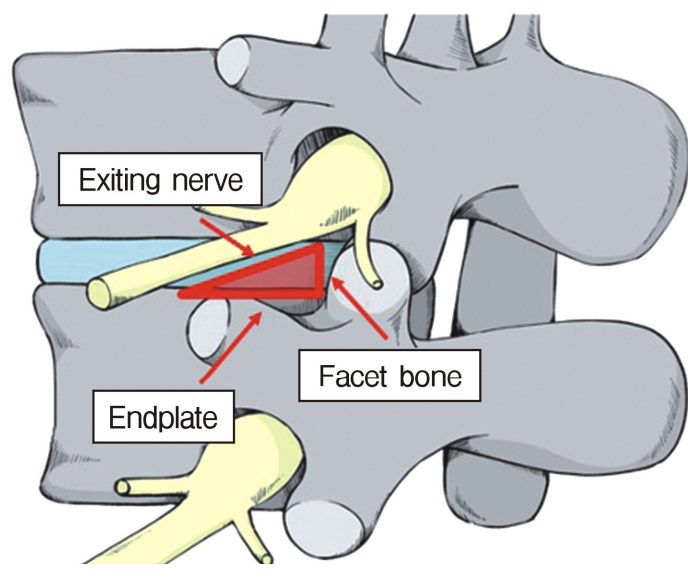

Figure 1. Schematic representation of Kambin's triangle (indicated by a red triangle). 
que is known as "TF-fullendo lumbar undercutting laminectomy". Nowadays, all types of spinal canal stenosis can be treated by fullendo surgery using a TF approach.

TF-fullendo surgery can also be performed to treat intradiscal disorders. The first such application of TF-fullendo surgery was when Ito et al. ${ }^{13)}$ successfully treated 15 cases of pyogenic discitis using full-endoscopic debridement and irrigation. The next application was intradiscal therapy in patients with severe annular tears and discogenic pain ${ }^{14,15)}$. The site of the annular tear was electrically coagulated using a bipolar radio-pulse device, a technique that has become known as "TF-fullendo thermal annuloplasty”. Most recently, TF-fullendo has been used for disc cleaning in patients with type 1 Modic change ${ }^{16)}$. After TF-fullendo cleaning surgery, low back pain disappears and inflammation seen on short tau inversion recovery images resolves. Nowadays, TF-fullendo surgery is performed worldwide for pyogenic discitis, discogenic pain, and type 1 Modic change ${ }^{13-16)}$.

The final challenge was insertion of a cage through Kambin's triangle. Various full-endoscopic lumbar interbody fusion techniques has been reported. For example, "percutaneous endoscopic lumbar interbody fusion" (PELIF) was described by Nakamura et al. in $2017^{17)}$ and subsequently by Wu et al. in 2018 ${ }^{18)}$ while Youn et al. ${ }^{19)}$ used the term "full-endoscopic lumbar interbody fusion" (FELIF), also in 2018. In the same year, Nagahama et al. ${ }^{20)}$ described their method, which included introducing an ovary-shaped cannula, and named it "percutaneous endoscopic transforaminal lumbar interbody fusion" (PETLIF); Kamson et al. ${ }^{21)}$ subsequently referred to this technique as "full-endoscopic transforaminal lumbar interbody fusion” (FETLIF). When describing a similar technique, Lewandrowski et al. ${ }^{22)}$ proposed the term "lordotic endoscopic wedge lumbar interbody fusion” (LEWLIF). Despite their different names, all these LIF techniques involve insertion of a cage through Kambin's triangle under full-endoscopic guidance (Figure 2). Therefore, the term "trans-Kambin triangle LIF" (KLIF) was finally proposed in 2019 23,24$)$.

We have developed a Fullendo-KILF system (Surgical Spine

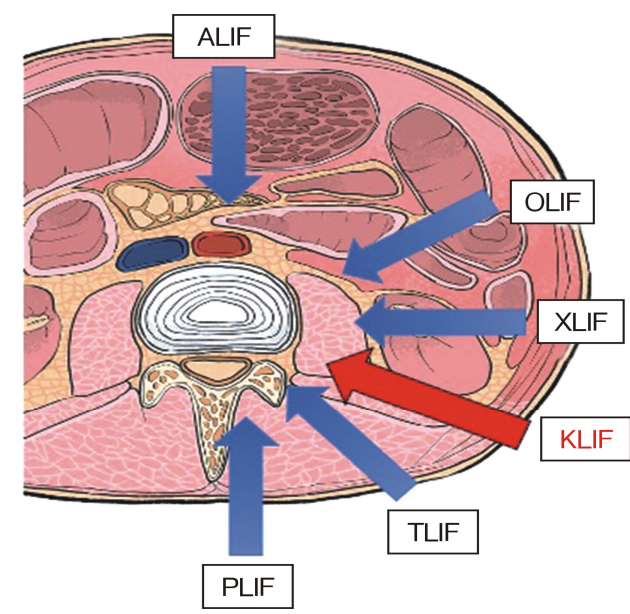

Figure 2. Anatomic site where the cage is inserted during a fullendoscopic trans-Kambin's triangle lumbar interbody fusion procedure.
Inc., Tokyo, Japan) that can be used to insert any type of cubic or expandable cage safely while protecting the exiting nerve root. In this paper, we introduce our fullendo-KLIF procedure and report our early clinical results for this system.

\section{SURGICAL PROCEDURE}

\section{Indications}

The best candidates for fullendo-KLIF at present are patients with a single-level disorder. Single-level fusion for conditions such as spondylolisthesis, scoliosis, discogenic pain, and Modic change can now be performed using this method.

Decompression is achieved indirectly by posterior reduction using a percutaneous pedicle screw system and inserting a cage. If direct decompression is needed for the exiting and/or traversing nerve root, TF-fullendo ventral facetectomy and/or foraminotomy is performed, respectively.

\section{Technique}

Neuromonitoring is performed throughout the surgery to avoid damage to the exiting nerve root. The procedure is explained here using a case of L2 degenerative spondylolisthesis as an example. Before fullendo-KLIF surgery, four percutaneous pedicle screws are inserted at L2 and L3 (Figure 3). The slippage is reduced and the disc height is extended as far as possible. The cannula of the full-endoscope is then docked on the superior articular process as shown in Figure 4. After adequate foraminoplasty, a guidewire with a safety ball at the tip is inserted into the disc (Figure 4, right panel). Adequate foraminotomy is then confirmed endoscopically. As shown in Figure 5, we usually create $12 \mathrm{~mm}$ of disc distance (4 times the 3-mm diameter of the surgical drill). An 8- to 10-mm cannulated spacer is inserted through an S-guide to enlarge the disc space (Figure 6). Using this device, the disc space is further widened to $10 \mathrm{~mm}$. Using the spacer, an open square cannula is inserted just inside the disc (Figure 7).

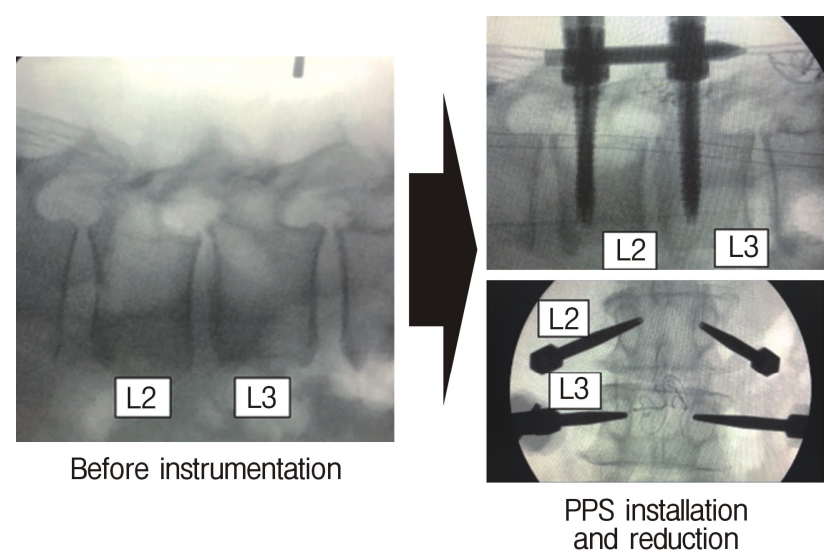

Figure 3. C-arm image obtained during surgery. Forward slippage of the vertebral body at L2 (left panel) is reduced after insertion of percutaneous pedicle screws (right panel). 
As shown in the figure, the open cannula completely protects the exiting nerve root. A specially designed curette or disc shaver (Figure 8) is then passed through the open cannula to empty the disc space and to curette the disc endplate. An autogenic or allogenic bone graft is implanted using a specially designed bone graft funnel (Figure 9, left panel). An expandable cubic cage is then inserted through the open cannula (Figure 10, left panel) and expands inside the disc (Figure 10, right panel). The cage has a width of $10 \mathrm{~mm}$ and a length of around $30 \mathrm{~mm}$. Plain radiographs obtained before and after surgery are used to confirm that the slipped vertebra is reduced and the disc space is opened up (Figure 11).

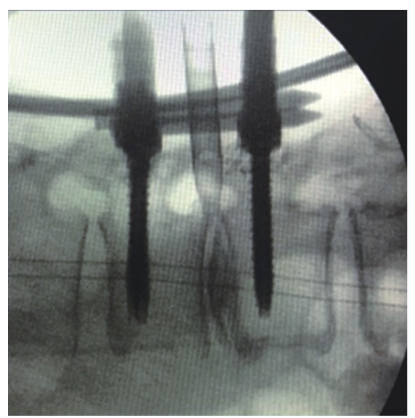

Cannula position during fullendoscopic foraminotomy
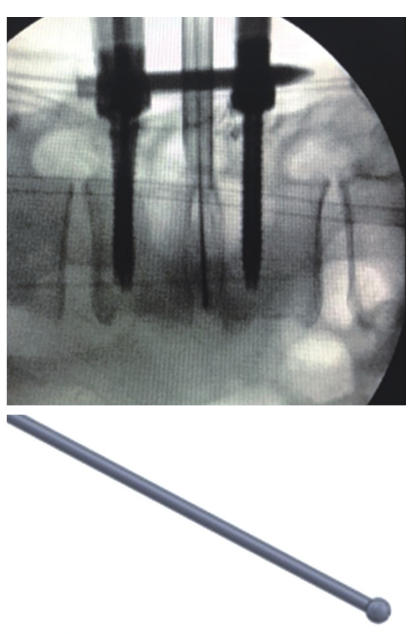

Safe-guide wire insertion through the cannula
Figure 4. C-arm image obtained during surgery. The left panel indicates the position of the cannula and the right panel shows insertion of a safety guidewire through the cannula.

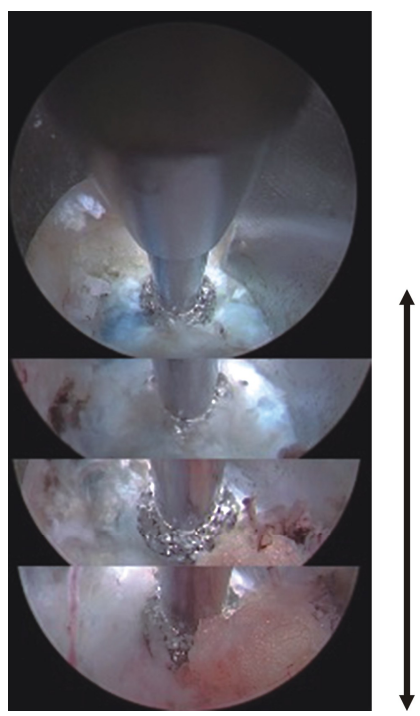

Distance of the exposed disc surface for the cage insertion is about $12 \mathrm{~mm}$.

$12 \mathrm{~mm}=4$ of $3 \mathrm{~mm}$ diamond heads

Figure 5. Endoscopic view after foraminotomy. Usually, a disc distance of $12 \mathrm{~mm}$ (4 times the 3-mm surgical drill diameter) is created for safe insertion of the cage.
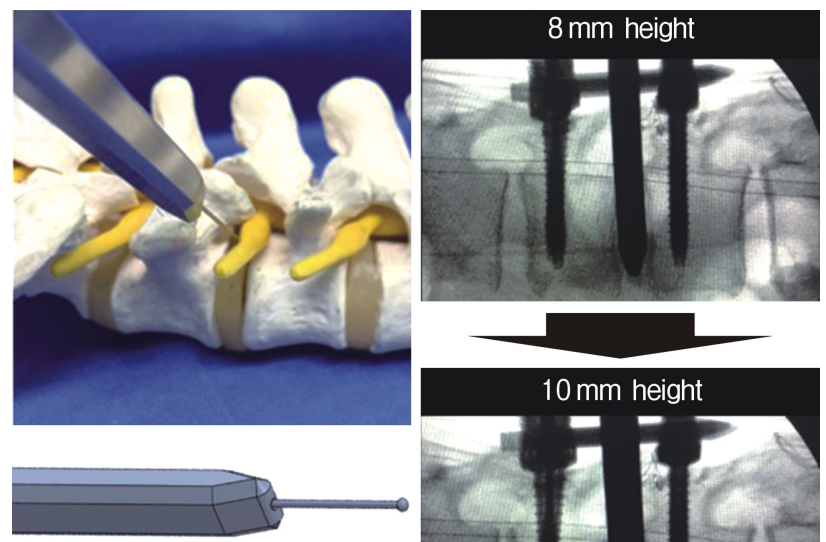

Cannulated $8 \mathrm{~mm} \times 10 \mathrm{~mm}$ spacer with safe-guide wire

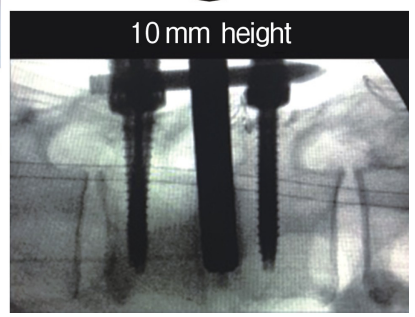

Figure 6. Insertion of the cannulated spacer. Through the S-guide, an $8^{-}$to $10-\mathrm{mm}$ cannulated spacer is inserted to widen the disc space to $10 \mathrm{~mm}$.

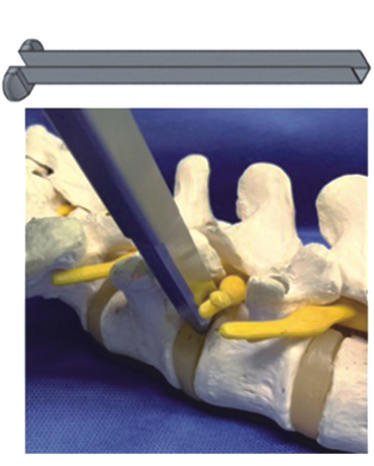

Open square cannula

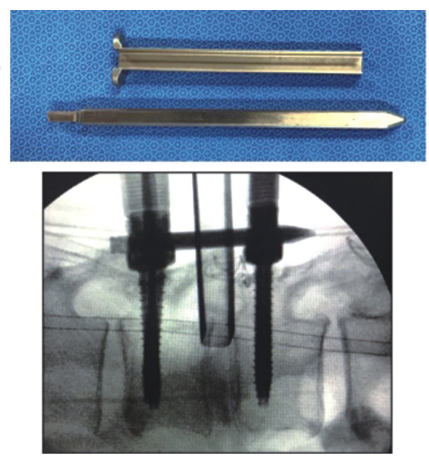

Open square cannula is inserted into the disc using the spacer
Figure 7. Insertion of the open square cannula just inside the disc using the spacer. The cannula protects the exiting nerve root.
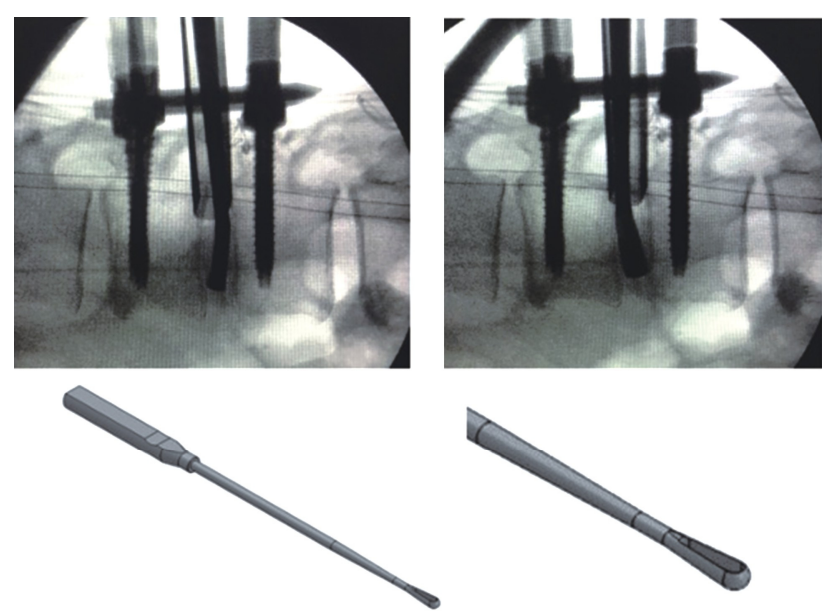

Disc space is shaved and clenaed up by special shaver

Figure 8. Cleaning inside the disc using a shaver through the open square cannula. 


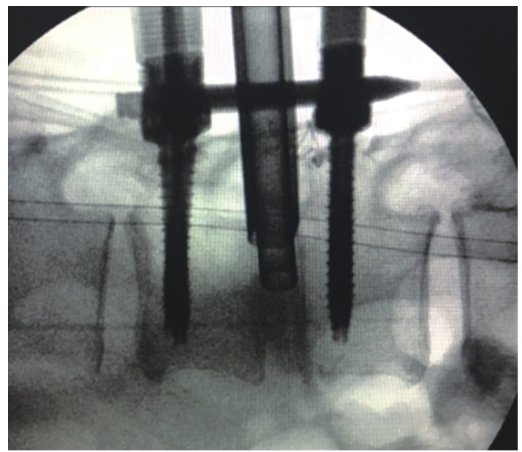

Bone grafting through the open square cannula

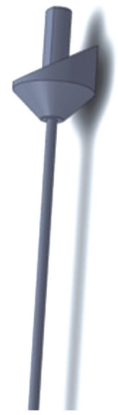

Special made bone graft funnel
Figure 9. Bone graft inserted through the open square cannula.
Before expansion

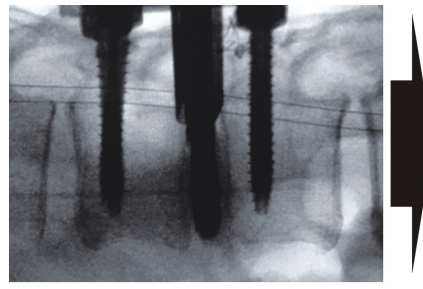

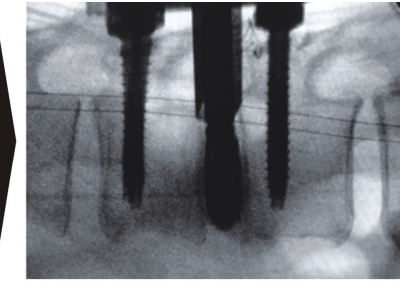

After expansion
Figure 10. Insertion of the cage through the open square cannula (left panel), which expands inside the disc (right panel).

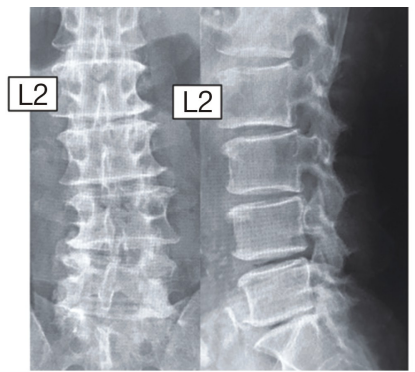

Before surgery

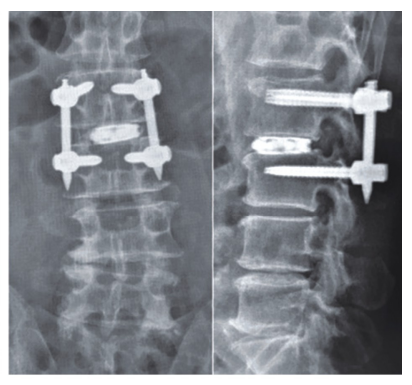

After surgery
Figure 11. Plain radiographs obtained before and after full-endoscopic trans-Kambin's triangle lumbar interbody fusion.

\section{METHODS}

Between 2018 and May 2020, we performed fullendo-KLIF surgery in 25 patients. The PETLIF system designed by Nagahama et al. ${ }^{20)}$ was used to insert the cage in the first 13 patients $(6$ male, 7 female). Since May 2020, we have used the fullendo-KLIF system in 12 patients ( 5 male, 7 female). The surgical complications and clinical outcomes in these patients were evaluated.

\section{RESULTS}

In our first patient, fullendo-KLIF surgery was performed at L4/5 using the PETLIF system. At the time of surgery, the patient complained of transient exiting nerve irritation at $L 4$, which improved within 2 weeks. There were no other complications, such as dural tear, traversing nerve injury, infection, or hematoma, in subsequent patients. Therefore, the overall complication rate was 4.0\% (1/25) for both types of KLIF (i.e., 7.7\% [1/13] for the PETLIF system and $0 \%$ for the fullendo-KLIF system). In retrospect, the complication that occurred in the first case probably reflects the surgical learning curve.

We have already reported the clinical results of the initial 10 cases who underwent fullendo-KLIF surgery using the PETLIF system $^{24)}$. The visual analog scale (VAS) scores for low back pain and leg pain significantly $(\mathrm{p}<0.05)$ decreased from 6.9 to 0.9 and from 6.0 to 0.9 , respectively. The clinical outcome was excellent in 8 cases and good in 2 according to the modified MacNab criteria. The clinical outcome was good or excellent in all 12 patients treated with the fullendo-KLIF system, although the follow-up duration was less than 1 year.

\section{DISCUSSION}

\section{Development of Transforaminal Full-endoscopic Spine Surgery}

TF-fullendo surgery was first used for discectomy ${ }^{4-6)}$. Initially, a herniated nucleus pulposus (HNP) at the disc level without migration was considered a good indication for inside-out TF-fullendo discectomy ${ }^{6)}$. Later, when the foraminoplasty technique was introduced $^{25)}$, a migrated HNP was also accepted as an indication for TF-fullendo discectomy ${ }^{26)}$. Choi et al. performed TFfullendo surgery in 59 patients with migrated HNP, which they corrected using a foraminoplasty technique, and found that $91.4 \%$ of patients had a satisfactory outcome. At first, HNP at L5-S1 was considered too difficult to treat because of obstruction by the iliac crest ${ }^{27}$. However, it was found that HNP at L5-S1 could be removed using foraminoplasty ${ }^{28)}$.

Next, the surgical indications were expanded to include decompression of spinal canal stenosis. Foraminal stenosis was the initial target for anatomical reasons. As far as we are aware, the first report on the foraminoplasty technique was published in 2003 by Ahn et al. ${ }^{29)}$, who performed posterolateral endoscopic foraminal decompression using a bone reamer, endoscopic forceps, and a laser under fluoroscopic guidance. However, other surgeons did not adopt this technique. With the advent of the surgical drill, further advances in bony decompression surgery were made. Lewandrowski et al. ${ }^{30)}$ subsequently used the surgical drill for foraminal decompression, as did Yamashita et al. ${ }^{31)}$.

Lateral recess stenosis was the next target. The ventral side of the facet joint needs to be removed to decompress the lateral recess using the TF approach ${ }^{10,11)}$. Sairyo and colleagues ${ }^{10,11)}$ then used the high-speed surgical drill to remove the hypertrophied facet joint, which introduced the concept of ventral facetectomy. Xie et al. ${ }^{32)}$ developed an alternative strategy for decompression of the lateral recess via the TF approach, which entailed using a 10-mm trephine rather than a high-speed drill. Finally the indications for TF-fullendo surgery were expanded 
to include central canal stenosis. Sairyo et al. ${ }^{12)}$ reported a procedure they described as TF-fullendo lumbar undercutting laminectomy for surgical decompression of the central stenosis. Therefore, any type of spinal canal stenosis is now a good indication for fullendo surgery.

Surgical intradiscal therapy started with debridement of infection and expanded to include thermal annuloplasty, disc cleaning surgery, and finally insertion of a cage into the dissected disc space.

\section{Nomenclature for Full-endoscopic Trans-Kambin's Triangle Lumbar Interbody Fusion}

Several LF techniques can be used to insert a cage in the intradiscal space and are named according to the anatomic site at which the cage is inserted. Examples include posterior LIF, anterior LIF, transforaminal LIF, direct lateral LIF, extreme lateral LIF, and oblique lateral LIF. Full-endoscopic insertion of a cage into the disc space via Kambin's triangle started in the late 2010s. This facet-sparing technique has been described variously as PELIF, PETLIF, FELIF, FETLIF, or LEWLIF, and is now known as $\mathrm{KLIF}^{23,24)}$.

The anatomically close relationship between the trans-Kambin technique and the TF technique has led to some confusion between KLIF and TLIF. Both methods include insertion of a cage through Kambin's triangle; however, Nagahama et al. ${ }^{20)}$ used the term "percutaneous endoscopic TLIF" while Kamson et al. ${ }^{21)}$ used the "full-endoscopic TLIF". Moreover, Morgenstern et al. ${ }^{33)}$ described their facet-sparing technique for inserting a cage through Kambin's triangle as "percutaneous TLIF"33). Tumialan et al. ${ }^{34)}$ pointed out that although the trans-Kambin and TF approaches seem to be similar, there are marked differences in the angle of trajectory and the bone work required. The TLIF approach entails widening Kambin's triangle and cannot be performed without total facetectomy. Therefore, our procedure is called KLIF rather than TLIF (Figure 12).

On the other hand, there has been reported the real full-endoscopic TLIF $^{35,36)}$. According to the report by $\mathrm{Wu}$ et al. ${ }^{35)}$ they do total facetectomy under the guidance of endoscope; then, a cage is inserted into the disc space. The authors called the technique as endo-TLIF. They clearly differentiate the technique

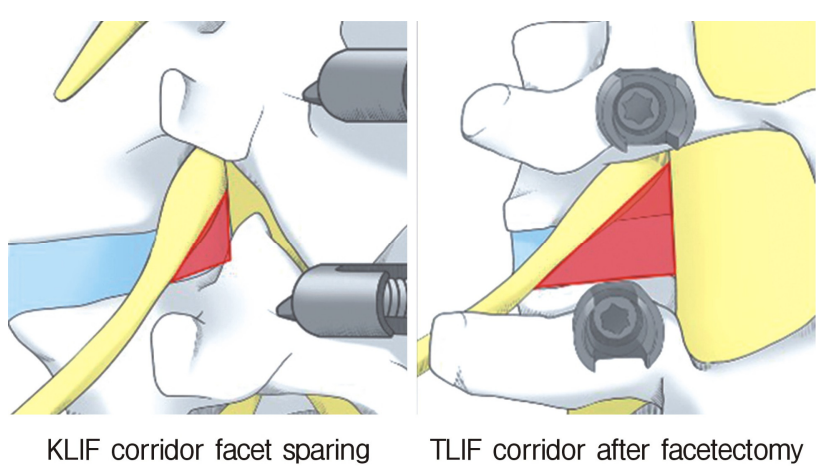

Figure 12. Schema of the difference between KLIF and TLIF. from the trans-Kambin Endo-LF. Our fullendo-KLIF is called transKambin endo-LIF in the paper. The other report is by Kim et al. $^{36)}$. Similarly they do total facetectomy with endoscope and insert a cage into the disc. They call the technique is endo-TLIF.

Actually, during their surgical procedure by We et al. ${ }^{35)}$ and Kim et $\mathrm{al}^{36}{ }^{36}$, total facetectomy is conducted prior to the cage insertion. Thus, this should be the endo-TLIF, not KLIF.

\section{Clinical Efficacy of Fullendo-KLIF}

In our initial 10 cases, the respective VAS scores for low back pain and leg pain decreased from 6.9 to 0.9 and from 6.0 to 0.9 . In these patents, the clinical outcome was excellent in 10 cases and good in 2 according to the modified MacNab criteria. The clinical outcome was also acceptable when the fullendo-KLIF system was used, albeit during a short follow-up period. Nakamura et al. ${ }^{35)}$ performed PELIF (trans-Kambin LIF) in 21 patients ( 8 male, 13 female), who were followed up for a mean of 20.3 months. The mean VAS scores improved from 6.1 to 1.9 for lower back pain in patients with severe disc degeneration without spondylolisthesis and from 7.6 to 1.0 for lower extremity symptoms in patients with spondylolisthesis. The clinical outcomes after these types of surgery are similarly good ${ }^{17-22)}$.

Of great concern is exiting nerve root injury (ENRI) during KLIF surgery. Lewandrowski et al. ${ }^{22)}$ reported the highest rate of ENRI during cage insertion via Kambin's triangle (60.4\%; 29/48 cases) and Morgenstern et al. ${ }^{33)}$ reported the second highest rate (22\%). Avoiding ENRI would be the most important determinant of the safety of KLIF surgery. As shown in Figure 5, the disc surface area can be observed endoscopically during the foraminotomy procedure. The width of the disc space from the facet bone to the exiting nerve must be at least $10 \mathrm{~mm}$, because width of a cage is a $10 \mathrm{~mm}$. Therefore, for safe insertion, we create a disc surface with a width of $12 \mathrm{~mm}$. ENRI has not occurred in the 12 patients we have treated using the fullendo-KLIF system.

\section{CONCLUSION}

In this paper, we have introduced our technique for inserting a cage into the disc space via Kambin's triangle under full-endoscopic guidance. We have named this procedure fullendo-KLIF (full-endoscopic trans-Kambin triangle interbody fusion). This is the most minimally invasive LIF surgery presently available and has acceptable clinical results while causing minimal damage to the back muscles. Clinical results were satisfactory. Endoscopic guidance is expected to enable safer cage insertion.

\section{CONFLICT OF INTEREST}

No potential conflict of interest relevant to this article.

\section{REFERENCES}

1. Kambin P, Sampson S: Posterolateral percutaneous suction-exci- 
sion of herniated lumbar intervertebral discs. Report of interim results. Clin Orthop Relat Res 207:37-43, 1986

2. Kambin P: Arthroscopic microdiskectomy. Mt Sinai J Med 58: 159-164, 1991

3. Hijikata S: A method of percutaneous nuclear extraction. J Toden Hosp 5:39, 1975

4. Yeung AT: The evolution of percutaneous spinal endoscopy and discectomy: state of the art. Mt Sinai J Med 67:327-332, 2000

5. Yeung AT, Tsou PM: Posterolateral endoscopic excision for lumbar disc herniation: Surgical technique, outcome, and complications in 307 consecutive cases. Spine 27:722-731, 2002.

6. Sairyo K, Egawa H, Matsuura T, Takahashi M, Higashino K, Sakai T, Suzue N, Hamada D, Goto T, Takata Y, Nishisho T, Goda Y, Sato R, Tsutsui T, Tonogai I, Kondo K, Tezuka F, Mineta K, Sugiura K, Takeuchi M, Dezawa A: State of the art: Transforaminal approach for percutaneous endoscopic lumbar discectomy under local anesthesia. J Med Invest 61(3-4):217-225, 2014

7. Sairyo K, Chikawa T, Nagamachi A: State-of-the-art transforaminal percutaneous endoscopic lumbar surgery under local anesthesia: Discectomy, foraminoplasty, and ventral facetectomy. J Orthop Sci Mar;23(2):229-236, 2018

8. Lewandrowski KU: "Endoscopic Transforaminal and Lateral Recess Decompression After Previous Spinal Surgery." Int J Spine Surg 12(2):98-111, 2018

9. Yeung A, Gore S: Endoscopic foraminal decompression for failed back surgery syndrome under local anesthesia. Int J Spine Surg Dec;1:8, 2014 doi: 10.14444/1022. eCollection 2014.

10. Sairyo K, K Higashino, K Yamashita, F Hayashi, K Wada, T Sakai, Y Takata, F Tezuka, M Morimoto, T Terai, T Chikawa, H Yonezu, A Nagamachi and Y Fukui: "A new concept of transforaminal ventral facetectomy including simultaneous decompre ssion of foraminal and lateral recess stenosis: Technical considerations in a fresh cadaver model and a literature review." J Med Invest 64(1-2):1-6, 2017

11. Sugiura $K$, Yamashita $K$, Manabe $H$, Ishihama $Y$, Tezuka F, Takata Y, Sakai T, Maeda T, Sairyo K: Prompt return to work after bilateral transforaminal full-endoscopic lateral recess decompression under local anesthesia: A case report. J Neurol Surg A Cent Eur Neurosurg Dec;22, 2020 doi: 10.1055/s-0040-1712463. Online ahead of print.

12. Sairyo K, Yamashita K, Manabe H, Ishihama Y, Sugiura K, Tezuka F, Takata Y, Sakai T, Omichi Y, Takamatsu N, Hashimoto A, Maeda T: A novel surgical concept of transforaminal full-endoscopic lumbar undercutting laminectomy (TE-LUL) for central canal stenosis of the lumbar spine with local anesthesia: A case report and literature review. J Med Invest 66(3-4):224-229, 2019

13. Ito M, Abumi K, Kotani Y, Kadoya K, Minami A: Clinical outcome of posterolateral endoscopic surgery for pyogenic spondylodiscitis: results of 15 patients with serious comorbid conditions. Spine (Phila Pa 1976). Jan;15;32(2):200-206, 2007

14. Tsou PM, Alan Yeung C, Yeung AT: Posterolateral transforaminal selective endoscopic discectomy and thermal annuloplasty for chronic lumbar discogenic pain: A minimal access visualized intradiscal surgical procedure. Spine J Sep-Oct;4(5):564-573, 2004

15. Manabe H, Yamashita K, Tezuka F, Takata Y, Sakai T, Maeda T, Sairyo K: Thermal Annuloplasty Using Percutaneous Endoscopic Discectomy for Elite Athletes with Discogenic Low Back
Pain. Neurol Med Chir (Tokyo). Feb;15;59(2):48-53, 2019

16. Sairyo K. Maeda T, Yamashita K, Tezuka F, Morimoto M, Yagi K, Kishima K, Sugiura K, Takeuchi M, Yamada Y, Takata Y, Sakai $\mathrm{T}$ : A novel surgical strategy for intractable chronic low back pain due to Modic type 1 change using transforaminal full-endoscopic disc cleaning surgery under local anesthesia: A case report and literature review. J Med Invest. In press

17. Nakamura $S$ and Taguchi M: Full Percutaneous Lumbar Interbody Fusion: Technical Note. J Neurol Surg A Cent Eur Neurosurg Nov;78(6):601-606, 2017

18. Wu J, Liu H, Ao S, Zheng W, Li C, Li H, Pan Y, Zhang C, Zhou Y: Percutaneous Endoscopic Lumbar Interbody Fusion: Technical Note and Preliminary Clinical Experience with 2-Year FollowUp. Biomed Res Int. Nov;19; 2018:5806037. doi: 10.1155/2018/ 5806037. eCollection 2018.

19. Youn MS, Shin JK, Goh TS, Lee JS: Full endoscopic lumbar interbody fusion (FELIF): Technical note. Eur Spine J Aug;27(8):19491955, 2018

20. Nagahama K, Ito M, Abe Y, Murota E, Hiratsuka S, Takahata M: Early Clinical Results of Percutaneous Endoscopic Transforaminal Lumbar Interbody Fusion: A New Modified Technique For Treating Degenerative Lumbar Spondylolisthesis. Spine Surg and Related Research 2018 epub ahead

21. Kamson S, Lu D, Sampson PD, Zhang Y: Full-Endoscopic Lumbar Fusion Outcomes in Patients with Minimal Deformities: A Retrospective Study of Data Collected Between 2011 and 2015. Pain Physician Jan;22(1):75-88, 2019

22. Lewandrowski KU, Ransom NA, Ramírez León JF, Yeung A: The Concept for A Standalone Lordotic Endoscopic Wedge Lumbar Interbody Fusion: The LEW-LIF. Neurospine Mar;16(1):8295, 2019

23. Sairyo K, Maeda T: Fullendo-KLIF for the anatomical nomenclature of the full-endoscope guided lumbar interbody fusion through the Kambin triangle: PELIF, PETLIF, FELIF, FE-TLIF or KLIF? EC Orthopaedics 10(9):743-745, 2019

24. Ishihama $Y$, Morimoto $M$, Tezuka F, Yamashita $K$, Manabe $H$, Sugiura K, Takeuchi M, Takata Y, Sakai T, Maeda T, Nagamachi A, Sairyo K: Full-endoscopic trans-Kambin's triangle lumbar interbody fusion (Fullendo-KLIF): Surgical technical and nomencla ture. J Neurol Surg A Cent Eur Neurosurg. In press

25. Henmi T, Terai T, Hibino N, Yoshioka S, Kondo K, Goda Y, Tezuka F, Sairyo K: Percutaneous endoscopic lumbar discectomy utilizing ventral epiduroscopic observation technique and foraminoplasty for transligamentous extruded nucleus pulposus: Technical note. J Neurosurg Spine Oct;13:1-6, 2015

26. Choi G, Lee SH, Lokhande P. Kong BJ, Shim CS, Jung B, Kim JS: Percutaneous endoscopic approach for highly migrated intracanal disc herniations by foraminoplastic technique using rigid working channel endoscope. Spine 33(15):E508-E515, 2008

27. Tezuka F, Sakai T, Abe M, Yamashita K, Takata Y, Higashino K, Chikawa T, Nagamachi A, Sairyo K: Anatomical considerations of the iliac crest on percutaneous endoscopic discectomy using a transforaminal approach. Spine J Dec;17(12):1875-1880, 2017

28. Abe M, Takata Y, Higashino K, Sakai T, Matsuura T, Suzue N, Hamada D, Goto T, Nishisho T, Goda Y, Tsutsui T, Tonogai I, Miyagi R, Morimoto M, Mineta K, Kimura T, Nitta A, Hama S, Higuchi T, C Jha S, Takahashi R, Fukuta S, Sairyo K: Fora- 
minoplastic transforaminal percutaneous endoscopic discectomy at the lumbosacral junction under local anesthesia in an elite rugby player. J Med Invest 62(3-4):238-241, 2015

29. Ahn Y, Lee SH, Park WM, Lee HY: Posterolateral percutaneous endoscopic lumbar foraminotomy for L5-S1 foraminal or lateral exit zone stenosis. Technical note. J Neurosurg Oct;99(3 Suppl):320323, 2003

30. Lewandrowski KU: Outside-in technique, clinical results, and indications with transforaminal lumbar endoscopic surgery: A retrospective study on 220 patients on applied radiographic classification of foraminal spinal stenosis. Int J Spine Surg Dec;1(8): 26, 2014

31. Yamashita K, Higashino K, Sakai T, Takata Y, Hayashi F, Tezuka F, Morimoto M, Chikawa T, Nagamachi A, Sairyo K: Percutaneous full endoscopic lumbar foraminoplasty for adjacent level foraminal stenosis following vertebral intersegmental fusion in an awake and aware patient under local anesthesia: A case report. J Med Invest 64(3-4):291-295, 2017

32. Xie P, Feng F, Chen Z, He L, Yang B, Chen R, Wu W, Liu B, Dong J, Shu T, Zhang L, Chen CM, Rong L: Percutaneous transforaminal full endoscopic decompression for the treatment of lumbar spinal stenosis. BMC Musculoskelet Disord Aug;21(1):546, 2020

33. Morgenstern C, Yue JJ, Morgenstern R: Full Percutaneous Transforaminal Lumbar Interbody Fusion Using the Facet-sparing, TransKambin Approach. Clin Spine Surg Feb;33(1):40-45, 2020

34. Nakamura S, Ito F, Ito Z, Shibayama M: Methods and Early Clinical Results of Percutaneous Lumbar Interbody Fusion. Neurospine Dec;17(4):910-920, 2020

35. Wu PH, Kim HS, Lee YJ, Kim DH, Lee JH, Jeon JB, Raorane HD, Jang IT: Uniportal Full Endoscopic Posterolateral Transforaminal Lumbar Interbody Fusion with Endoscopic Disc Drilling Preparation Technique for Symptomatic Foraminal Stenosis Secondary to Severe Collapsed Disc Space: A Clinical and Computer Tomographic Study with Technical Note. Brain Sci Jun;15;10(6): 373, 2020

36. Kim HS, Wu PH, Lee YJ, Kim DH, Jang IT: Technical Considerations of Uniportal Endoscopic Posterolateral Lumbar Interbody Fusion: A Review of Its Early Clinical Results in Application in Adult Degenerative Scoliosis. World Neurosurg Jan;145: 682-692, 2021 